\title{
The relationship between brain activity pattern and math skill: An event-related potential based study
}

\author{
Shiva Taghizadeh ${ }^{1}$, Ali Jahan², Touraj Hashemi ${ }^{3}$, Mohammad Ali Nazari ${ }^{4 *}$
}

1. PhD Student of Cognitive Neuroscience, Faculty of Education and Psychology, University of Tabriz, Tabriz, Iran

2. Assistant Professor of Neuroscience, Brain and Cognition Lab, Tabriz University of Medical Sciences, Tabriz, Iran

3. Professor of Psychology, Department of Psychology, Faculty of Education and Psychology, University of Tabriz, Tabriz, Iran

4. Professor of Cognitive Neuroscience, Faculty of Education and Psychology, University of Tabriz, Tabriz, Iran

Recieved: 19 Mar. 2020

Revised: 23 Aug. 2020

Accepted: 1 Sep. 2020

\section{Keywords}

ERP

Math skill

Mental arithmetic

Mismatch negativity

\section{Corresponding author}

Mohammad Ali Nazari, Professor of Cognitive Neuroscience, Faculty of Education and Psychology, University of Tabriz, Tabriz, Iran

Email: Nazaripsycho@yahoo.com

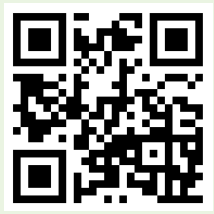

\section{Abstract}

Introduction: Cognitive neuroscience has developed several indicators and tools for use in education. It has also led to the discovery of neuro-markers to assess learning and individual differences. The present study aimed to investigate individual differences in mathematical skills using event-related potentials.

Methods: Thirty-eight right-handed participants were assigned into two groups of high and low math skills. After that, their electroencephalograms were recorded during the completion of a number verification task. The accuracy scores, reaction times, and peak amplitude of the negativity in the 200-400 ms time window were analyzed. Data were analyzed using repeated measures analysis of variance.

Results: The results showed that the high skill group performs better in the accuracy and reaction time than the low skill group $(\mathrm{P}<0.001)$. The amplitude of the study's ERP component was significantly higher in the high skill group at the parietal area, whereas in the low skill group, the component was more prevalent in frontal and prefrontal areas. Besides, there was a significant difference between the peak amplitude of anterior and posterior areas in the low skill group, while no such difference was observed in the high skill group.

Conclusion: In general, students with different math skills demonstrated different brain activity and the negative component in the time window of the $200-400 \mathrm{~ms}$ was different for individual differences in math performance.

Citation: Taghizadeh Sh, Jahan B, Hashemi T, Nazari MA. The relationship between brain activity pattern and math skill: An event-related potential based study. Advances in Cognitive Sciences. 2020;22(3):68-78. 


\title{
ارتباط بين الكوى امواج مغزى و مهارت رياضى: مطالعه مبتنى بر يتانسيل وابسته به رويداد
}

\author{
(iD) شيوا تقىزاده'، على جهان
}

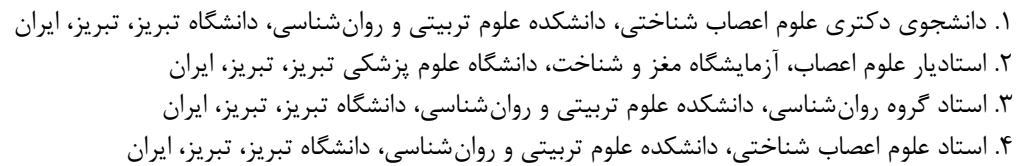

\section{ars}

مقلهمه: علوم اعصاب شناختى در حال حاضر خندين شاخص و ابزار براى استفاده در حوزه آموزش ايجاد كرده است كه

منجر به كشف نشان گرهاى عصبى براى ارزيابى و بررسى روند يادكيرى و تفاوتهاى فردى شده است. هدف اين يزوهش بررسى تفاوتهاى فردى در مهارت هاى رياضى در سطح سايكوفيزيك و يتانسيل هاى وابسته به رويداد بود. روش كار: در اين مطالعه نيمه تجربى، سى و هشت شركت كننده راست دست از دانشجويان رشتههاى مهندسى و غير مهندسى در دو كروه با مهارت رياضى بالا و پايين جاى كذارى شدند. سيس در حين انجام تكاليف رايانهاى محاسبات

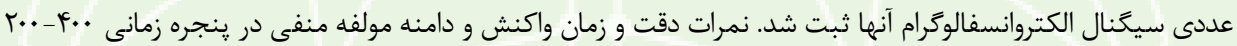
ميلىثانيه مورد بررسى قرار گرفت. دادها با روش تحليل واريانس مكرر تحليل شدند. يافته ها: كروه مهارت پايين در دقت و زمان واكنش نسبت به گروه ديخر به طور معنادار عملكرد پاييينترى نشان داد

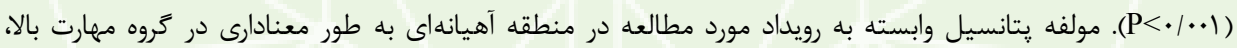
دامنه بزركترى داشت، در حالى كه دامنه اين مولفه در گروه مهارت پايين، در منطقه پِيشانى و پيش بيشانى بيشتر بود. همجنين، بين دامنه نواحى قدامى و خلفى در گروه مهارت پاييين، اختلاف معنادارى وجود داشت در حالى كه خنين اختلافى در كروه مهارت بالا مشاهده نشد. نتيجه كيرى: به طور كلى افراد با مهارت رياضى متفاوت فعاليت مغز متفاوتى نشان دادند و مولفه منفى در ينجره زمانى

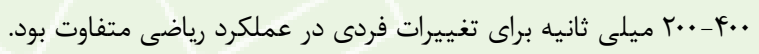

دريافت:

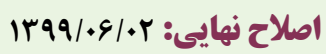

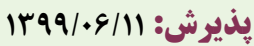

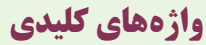
يتانسيل وابسته به رويداد محاسبات عددى لماسل تفاوت هاى فردى مليات عددى

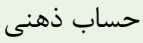

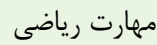

نويسنله مسئول محمد على نظرى، استاد علوم اعصاب شناختى، دانشكده علوم تربيتى و روانشناسى، دانشكاه تبريز، بلوار و ب بهمن، تبريز

ايميل: Nazaripsycho@yahoo.com

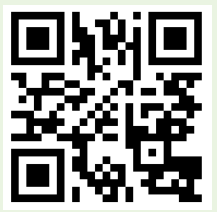

dol doi.org/10.30699/icss.22.3.68

مقلدمه

درباره اعداد و روابط آنها است. اين سيستم در لوب آهيانهاى مغز در هر دو نيمكره واقع شده است ( (1) . اين سيستم در كود كان و بزر گسالان در انجام تكاليف عددى اوليه فعال است، اما بهنظر مىرسد در طول تحول تخصصىتر مىشود. علاوه بر اين، كودكان داراى اختلال يادگيرى رياضى در اين منطقه نسبت به كودكان معمولى فعاليت ضعيفترى
كاربرد علوم اعصاب براى مطالعه يردازش رياضى موجب درك فراترى

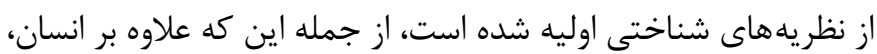
نخستى ها، دوزيستان و يرندگًان نيز به طور ذاتى توانايى تميز كميتهاى عددى را دارند. اين توانايى، حس عددى (Number sense) نام گرفته است. محققان نشان دادهاند كه "حس عددى" مسئول دانش بنيادى 
كرفتند كه اين مولفه نشاندهنده يردازش دركيرى ذهنى درونزا در مغز انسان است؛ فرايندى كه حاكى از توانايى شناختى عمومى و خودكار است. در آزمايش ديخرى با استفاده از تكليف تميز عددى نشان دادند

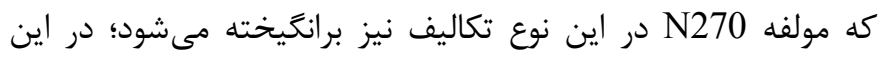

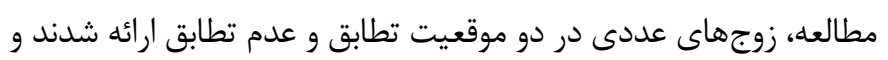

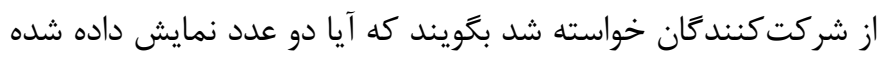
يكسان است (موقعيت تطابق) يا خير (موقعيت عدم تطابق)، در موقعيت

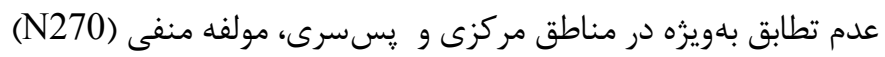
را كزارش كردند و اين واقعه نوروفيزيولوزيكى را بازتاب يردازش عدم هري تطابق عدد در مغز تفسير كردند (1)). تروهى از دانشمندان يك مؤلفه

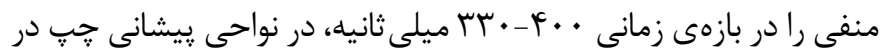
مقابل آهيانهاى راست، به عنوان يك اثر انتظار استراتزيك تزارش كرداني و اذعان داشتند كه تشخيص تطابق عددى با تشخيص نقض انتظارات استراتزيك به لحاظ زمانى هم يوشانى دارند (1 ال).

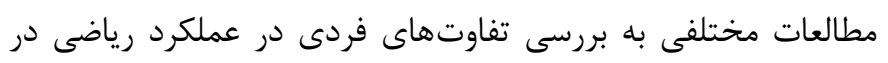

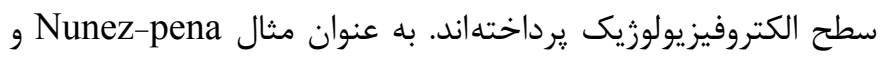

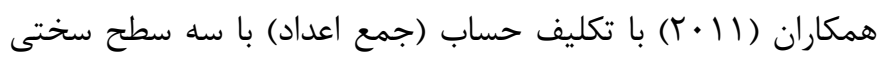

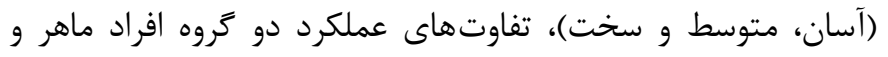
ضعيف در حساب را با بررسى يتانسيل هاى وابسته به رويداد برانگيخته مطالعه كردند. در اين مطالعه يتانسيل هاى وابسته به مرحله توليد

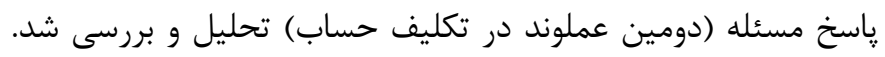

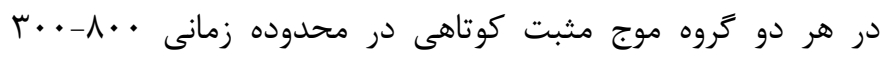

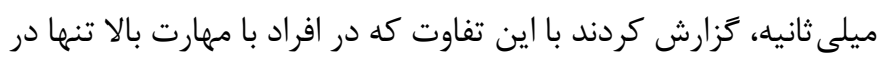

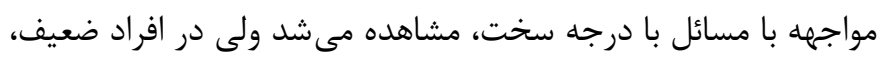

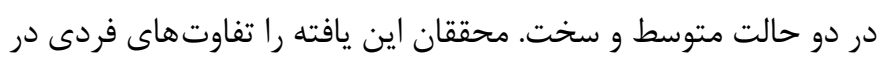

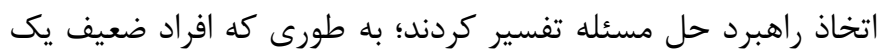
راهبرد حل مسئله براى مسائل سخت و متوسط استفاده مى كنند (r) (1).

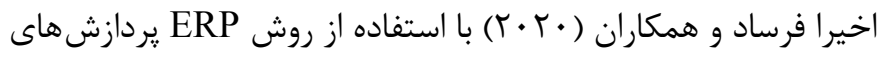

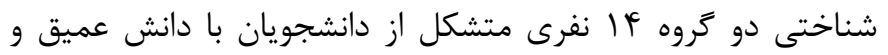

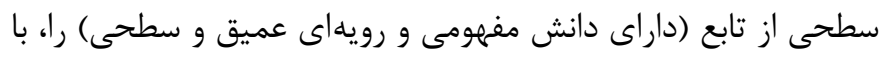

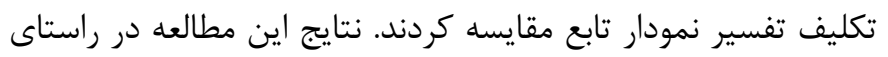

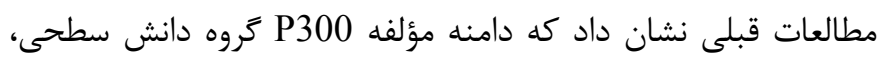

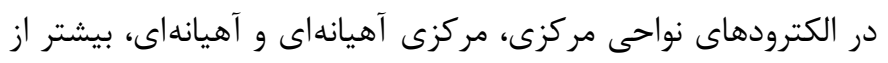
گروه دانش عميق است. به طورى كه انجام تكليف تفسير نمودار تابع، درئ

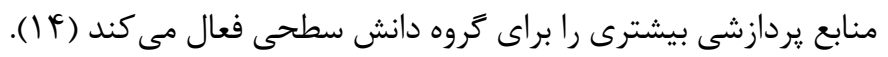
در مطالعات فوق، يتانسيل هاى وابسته در انواع تكاليف رياضى بررسى ترى شده است (PRP و P300) كه تاكيد بيشترى بر يردزاشهاى
نشان مىدهند. اين نتايج نشان مىدهد جَكونه تصويربردارى عصبى

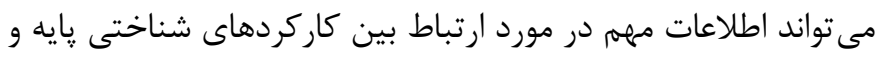

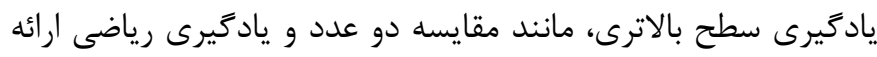

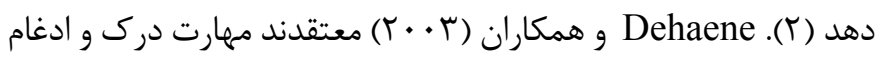
processing مفاهيم اساسى و اوليه عددى، مانند يردازش بزر (Y).

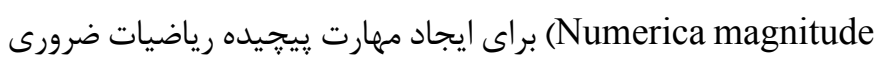

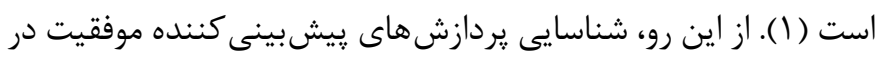

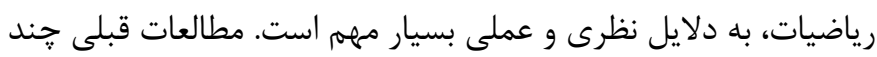

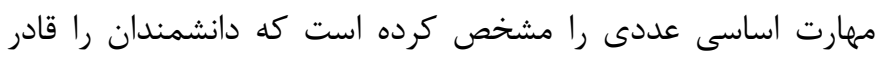

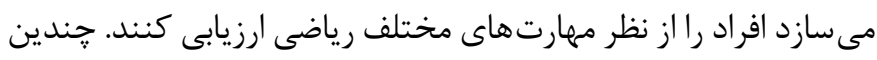
مطالعه تصويربردارى عصبى ارتباط بين فعاليت مغز هنعام انجام تكليف مقايسه عددى را با پيشرفت رياضى يافتهاند (ه-؟ّ).

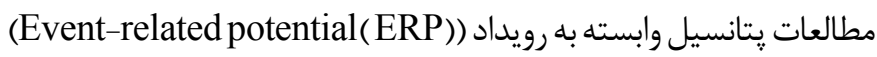

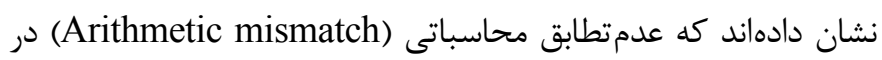
تكاليف شامل عمليات جمع، تفريق و ضرب و تكاليف تطبيق عددى داندي (Number matching tasks) مولفهاى با خصوصيات مشابه به (MMN) (مولفهاى كه در مواجهه با فماليا محرك متفاوت در يك مجموعه محرك مطابق با هم مشاهده مى تردد) كه در اجراى تكاليف حسابى ديده مىشود (9). محققان اين يديده را در

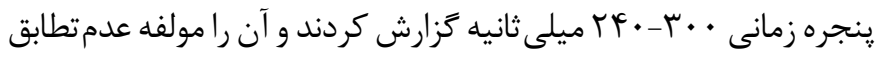

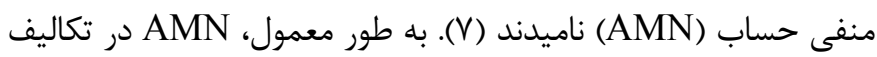

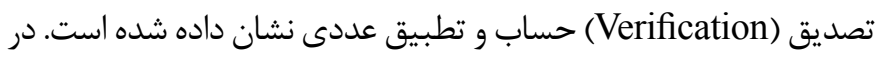
تكاليف تصديق حساب، شركت كنند

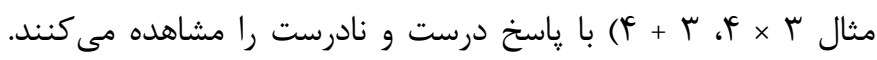

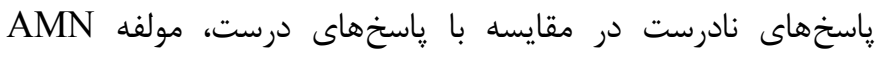

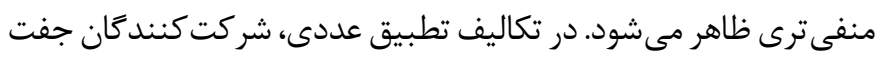
اعداد را به صورت سريالى مشاهده مى كنند كه ممكن است اين دو عدد يا باهم مطابقت و يا عدم تطابق داشته باشند (^). مقادير غير منطبق بيشتر

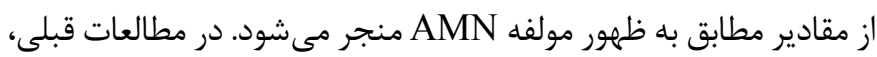

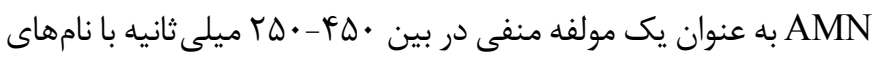

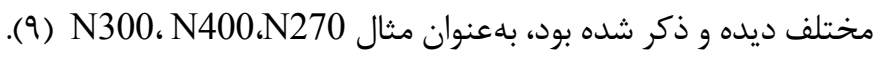

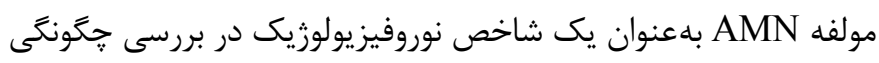

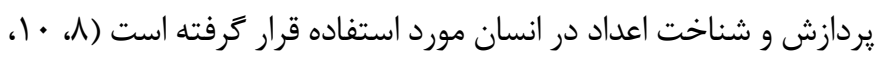
(1). با اين حال، طبيعت كاربردى اين اثر هنوز مشخص نشده است.

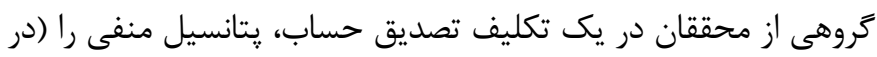

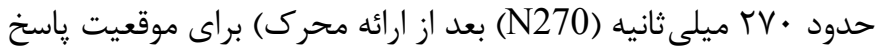
نادرست به محاسبه ذهنى بيشبينى شده، كزارش دادند. آنها نتيجه 
رياضى در برنامه درسى مشغول تحصيل بودند. اطلاعات مربوط به 9 شركت كننده به علت وجود دادهاى يرت، خطاهاى بالاى ينجاه درصد

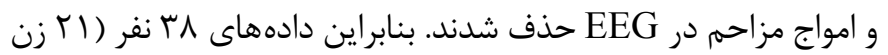

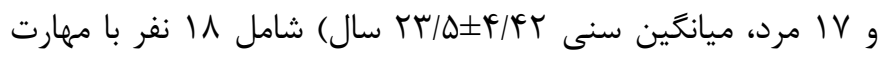

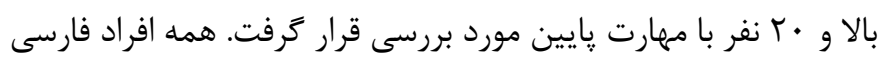

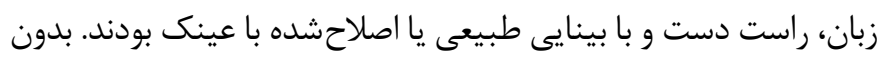

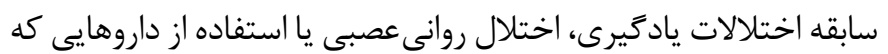

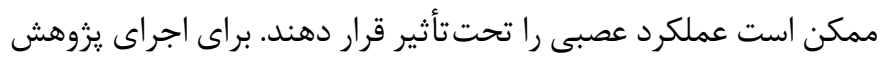

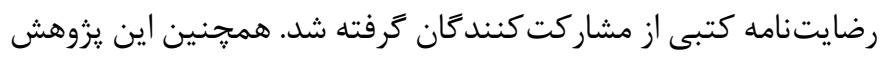
داراى كد اخلاقى از كميته اخلاق يزوهشى دانشكاه علوم يزشكى تبريز به شناسه (IR.TBZMED.REC.1398.058) است.

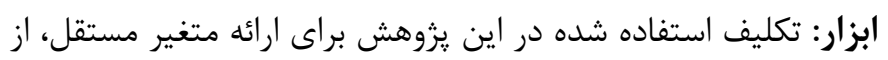

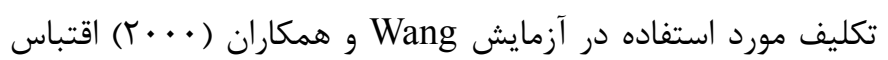

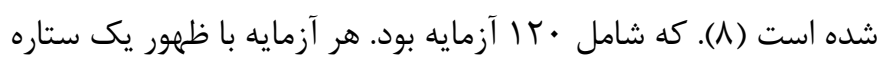

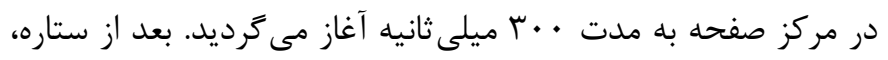

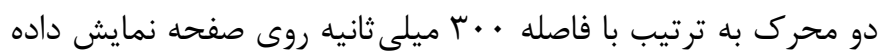
مى شد. محرك اول يك محاسبه ساده عددى (مانند

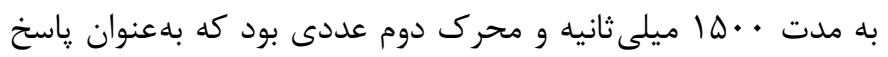
محاسبه عددى به مدت ... . ميلى ثانيه ارائه مىشدند. جواب ارائه

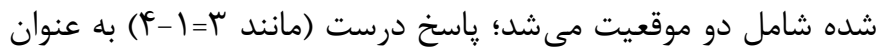

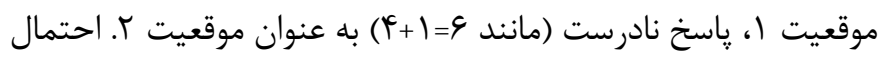

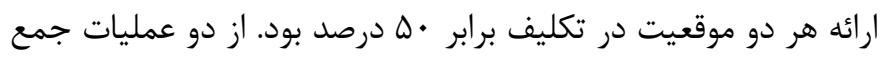

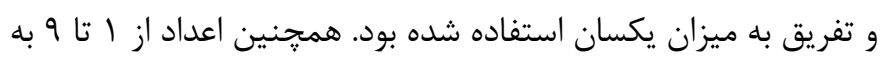
احتمال ارائه يكسان داشتند. علامت ستاره براى ارائه آزمايه دوم ب ثانيه

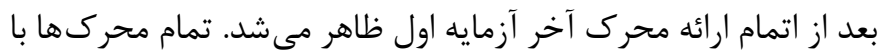
رنغ مشكى با زمينه سفيد نمايش داده مى شدند (شكل ()).
يِيجيده ر و غيرخودكار حساب بوده است. در حالى كه با توجه به

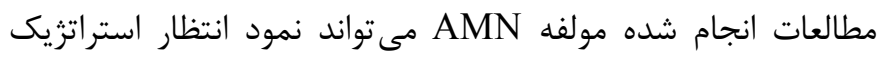

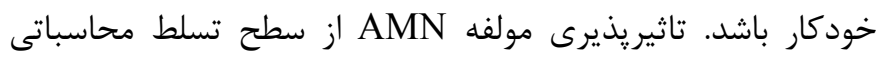

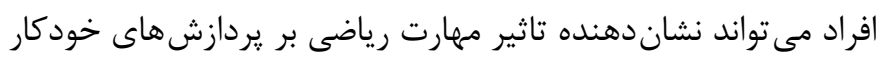

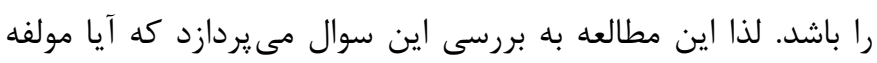

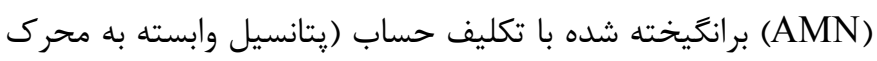

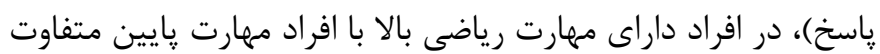

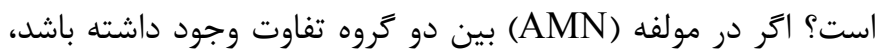

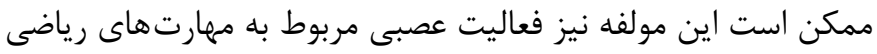
را منعكس كند كه در اين صورت مى تواند به عنوان يك مولفه مربوط

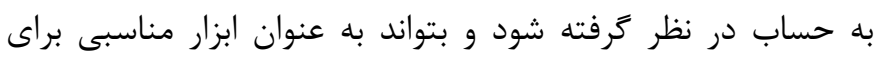

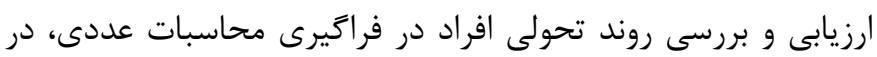
سطح مغز و شناخت به كار برود.

\section{روش كار}

اين مطالعه با توجه به اهداف از نوع كاربردى و با توجه به شيوه جمع آورى دادهها از نوع نيمه آزمايشى بود. جامعه آمارى شامل دانشجويان دختر و پسر شاغل به تحصيل در رشتههاى مهندسى و علوم انسانى در سال

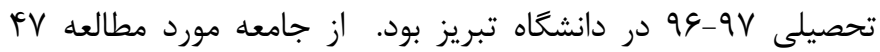

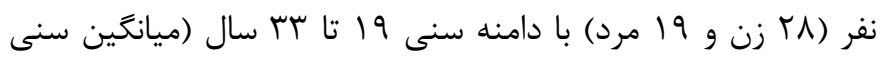
ش

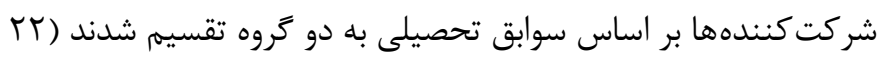

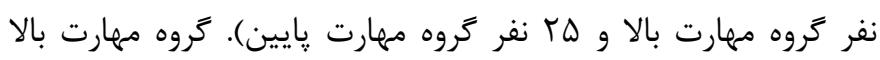

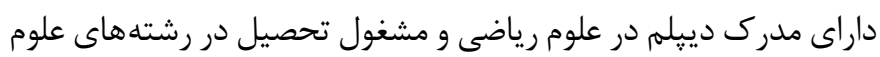

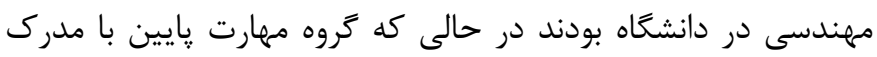

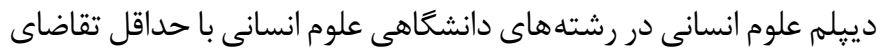

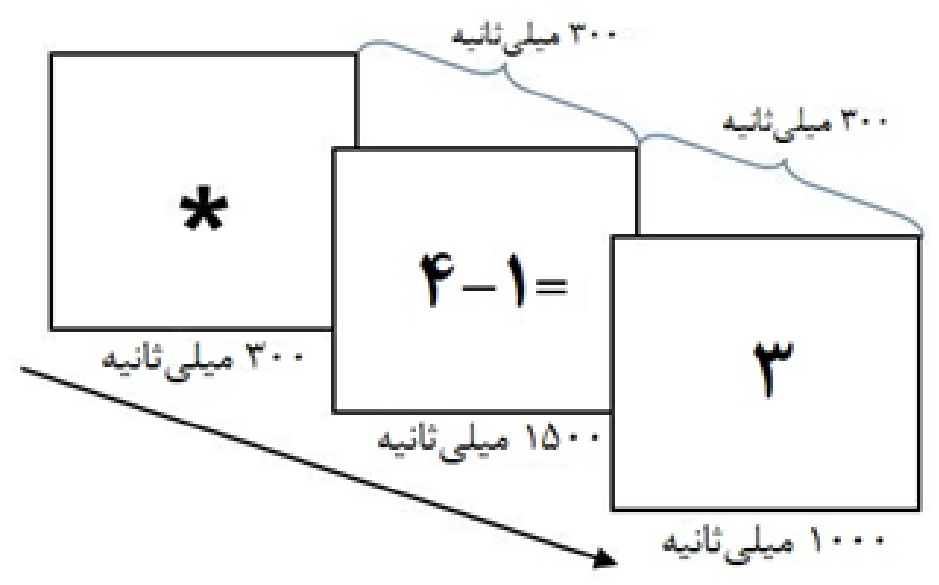

شكل ا. طرح شماتيك آزمايههاى ارائهشده در تكليف محاسبات عددى 
سگمنتهاى الكتروانسفالوگرافى از • · ميلى ثانيه قبل از شروع محرى دوم تا . • ا ميلى ثانيه بعد از آن براى ميانگين گيرى استخراج شدند. براى تك تك آزمودنى ها ميانگين دامنه موج يتانسيل وابسته

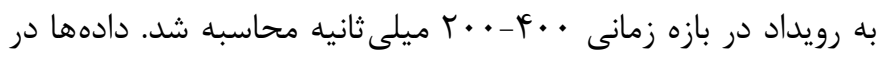
هشت منطقه مغزى بررسى شدند. تحليل واريانس با اندازهخيرىهاى مكرر براى بررسى تفاوت ميانگينها انجام شد. بدين منظور، متغير گروه (مهارت يايين و بالا) به عنوان عامل بين گروهى و متغيرهاى؛ موقعيت

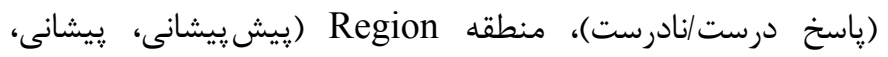

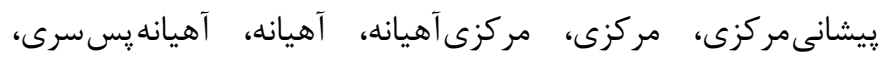
يس سرى)، نيمكره (ج)، مركزى، راست) به عنوان عوامل درون گروهى در نظر كرفته شدند. در صورت برقرار نبودن فرض كرويت، تصحيح

$$
\text { گرين هاوس_كايزر به كار رفت. }
$$

يافته ها نتايج رفتارى آمار توصيفى متغيرهاى رفتارى اين يزوهش در جدول ا ذكر شده است. نتايج تحليل واريانس نشان داد كه اثر اصلى گروه معنادار است

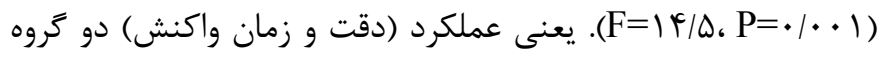
به طور معنادارى متفاوت است. در بررسى تعقيبى، مقايسه هاى زوجى نشان داد كه در هر دو موقعيت، زمان واكنش در گروه مهارت يايين با

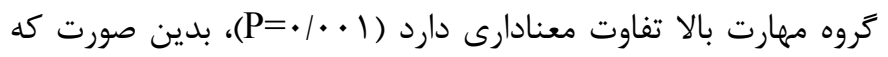

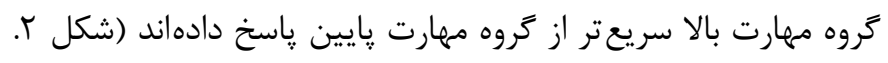
سمت راست). همجنين، گروه مهارت بالا نسبت به گروه مهارت يايين

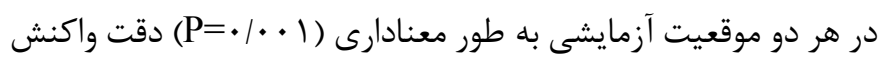
بيشترى نشان دادند (شكل r. سمت جِّ). نتايج يتانسيل هاى وابسته به رويدان در حين اين كه شركت كنند براى عمليات ساده رياضى درست هست يا نه مولفه AMN در ينجره

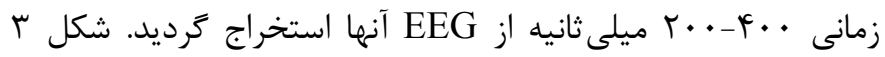
الگوى مولفه مذكور را در دو موقعيت درست و نادرست به تفكيك ماتى دو گروه مورد مطالعه در مناطق قدامى و خلفى نشان مى دهد. در

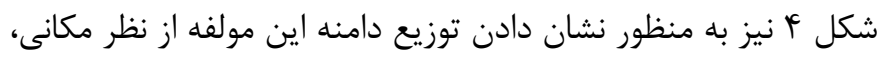
تويوكرافى تغييرات ولتاز اين مولفه در باع الكترود ترسيمى شده است. به منظور بررسى معنادارى تفاوت ميانگين هاى دامنه قله مولفه

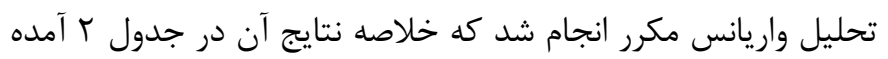
است. اين تحليل وجود تعامل معنادار را بين منطقه مغزى و گروه، موقعيت آزمايش و نيمكره و منطقه مغزى و موقعيت نشان داد. همجنين
روش اجرا: اتكليف مورد نظر در صفحه نمايش ال ا اينج در فاصله هفتاد سانتى مترى از مشاركت كنندهها نمايش داده شد. از شركت كنندكان خواسته شد با حداقل حركت فيزيكى در آرامش نشسته و به علامت ستاره در وسط نمايش محاسبات رياضى ساده را مشاهده خواهند كرد، در مورد صحت ياسخ نمايش داده شده در يايان هر مسئله داورى كنند و به محض ديدن

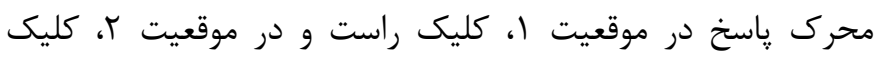
پֶٍ را فشار دهند؛ جهت متوازنسازى متقابل (Counterbalance)، كليد پاسخ در نيمى از شركت كنندهها برعكس بود. براى هر موقعيت، محاسبات رياضى به طور تصادفى ارائه شد. تكليف با استفاده از نرمافزار (محصول شركت ANT eevoke هلند) طراحى و اجرا شد. در حين اجراى تكليف، به صورت همزمان الكتروآنسفالوگرافى شركت كنندهها ثبت شد. آزمايش به صورت انفرادى اجرا شد و حدود • له دقيقه طول كشيد. جلسه آزمايش اصلى با يك تمرين كوتاه شروع مىشد كه هيج

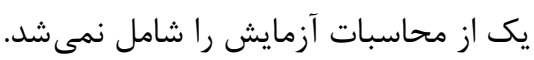
ثبت يتانسيل وابسته به رويداد: الكتروآنسفالوگرافى افراد به صورت ييوسته با استفاده از كلاه WaveGuard (محصول شركت ANT،

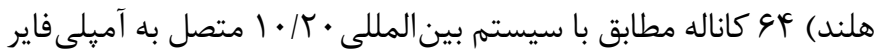
• • • هرتز ثبت شد. الكترود زمين DC DC mastoid) بود و سيخنال ها نسبت به مرجع متوسط ماستوييدها AFz

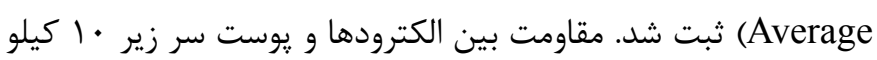
اهم نخه داشته شد. هيش يردازش سيخنال: سيخنالهاى الكتروانسفالوگرام به صورت آفلاين با استفاده از نرمافزار متلب (جعبه ابزار EEGLAB) ابتدا با لمآ

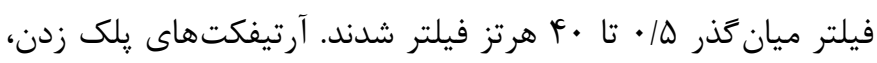
حركات جشم و تنشهاى عضلانى با استفاده از الكوريتم تحليل مؤلفه هاى مستقل (ICA) شناسايى و اصلاح شدند. ساير آرتيفكتها

نيز به صورت جشمى حذف شدند.

\section{روش تجزيه و تحليل دادهها} دادههاى رفتارى

براى تجزيه وتحليل دادهها در بخش آمار توصيفى، از ززارش فراوانى،

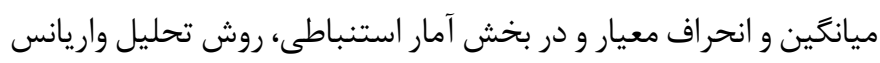
با اندازه خيرىهاى مكرر براى تحليل دادهها انتخاب شد. نمرات دقت واكنش (درصد ياسخهاى صحيح به تعداد كل آزمايه هاى هر موقعيت) و زمان واكنش افراد با استفاده از نرمافزار TM eevoke محاسبه شد. براى بررسى هاى آمارى از نرمافزار SPSS-22 استفاده شد.

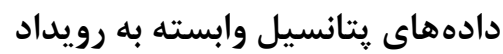


در گروه مهارت بالا دامنه قله در مناطق قدامى به خلفى متفاوت نبود (شكل fأ و شكل ه الف). مقايسه هاى زوجى انجام شده در هشت منطقه به طور جداگانه نشان داد كه صرف نظر از عوامل گروه و نيمكره، دامنه

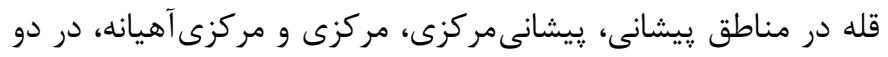
موقعيت نادرست و درست به طور معنادارى متفاوت است ( ( + • • (P=).
اثر اصلى عاملهاى موقعيت، ناحيه و نيمكره معنادار بود. همانطور كه در شكل أ و شكل ه ب نشان داده شده است، در گروه مهارت پايين به طور معنادارى قله مولفه AMN در مناطق ييش ييشانى و ي يشانى نسبت به مناطق خلفى دامنه منفى تر است. علاوه بر اين، در موقعيت نادرست نسبت به موقعيت درست دامنه قله بزرگتر بود. در صورتى كه بـ

جدول ا. اطلاعات توصيفى متغيرهاى رفتارى يزوهش

\begin{tabular}{|c|c|c|c|c|c|c|c|c|c|c|}
\hline \multicolumn{2}{|c|}{ تعداد } & \multicolumn{2}{|c|}{ بيشترين } & \multicolumn{2}{|c|}{ كمترين } & \multicolumn{2}{|c|}{ انحراف معيار } & \multicolumn{2}{|c|}{ ميانغين } & \multirow{3}{*}{ كروه } \\
\hline مههارت & مهارت & مهارت & مهارت & مهارت & مهارت & مهارت & مهارت & مههارت & مهارت & \\
\hline يايين & بالا & هايين & بالا & يايين & بالا & يايين & بالا & يايين & بالا & \\
\hline r. & 11 & rq & r & 19 & r) & T/TF & $r|\Lambda|$ & $r \cdot / q$ & $r q / \Lambda$ & سن \\
\hline$r$. & 11 & $91 / \pi$ & $1 .$. & $r \varepsilon / V$ & $\wedge$. & $r \cdot 19$ & $\Delta / \cdot \Lambda$ & $V F / V$ & $9 \Delta / r$ & موقعيت درست واكنش \\
\hline$r$. & 11 & 991 & 999 & Q9V & זrt & 119 & $\Lambda F / F$ & VVD & $\Delta G r$ & زمان واكنش درست \\
\hline r. & 11 & $90 / 9$ & $9 \vee / \Lambda$ & $|f| / 1$ & VG/V & $10 / \Lambda$ & $\Delta / V r$ & VG/V & $9 T / 4$ & موقعيت نادرست واكنش \\
\hline$r$. & 11 & $1 \cdot r \Lambda$ & VAr & 9.9 & FYF & 1TE & Ar & Arr & GYu & زموقعيت نادرست واكنش \\
\hline
\end{tabular}

دقت واكنش
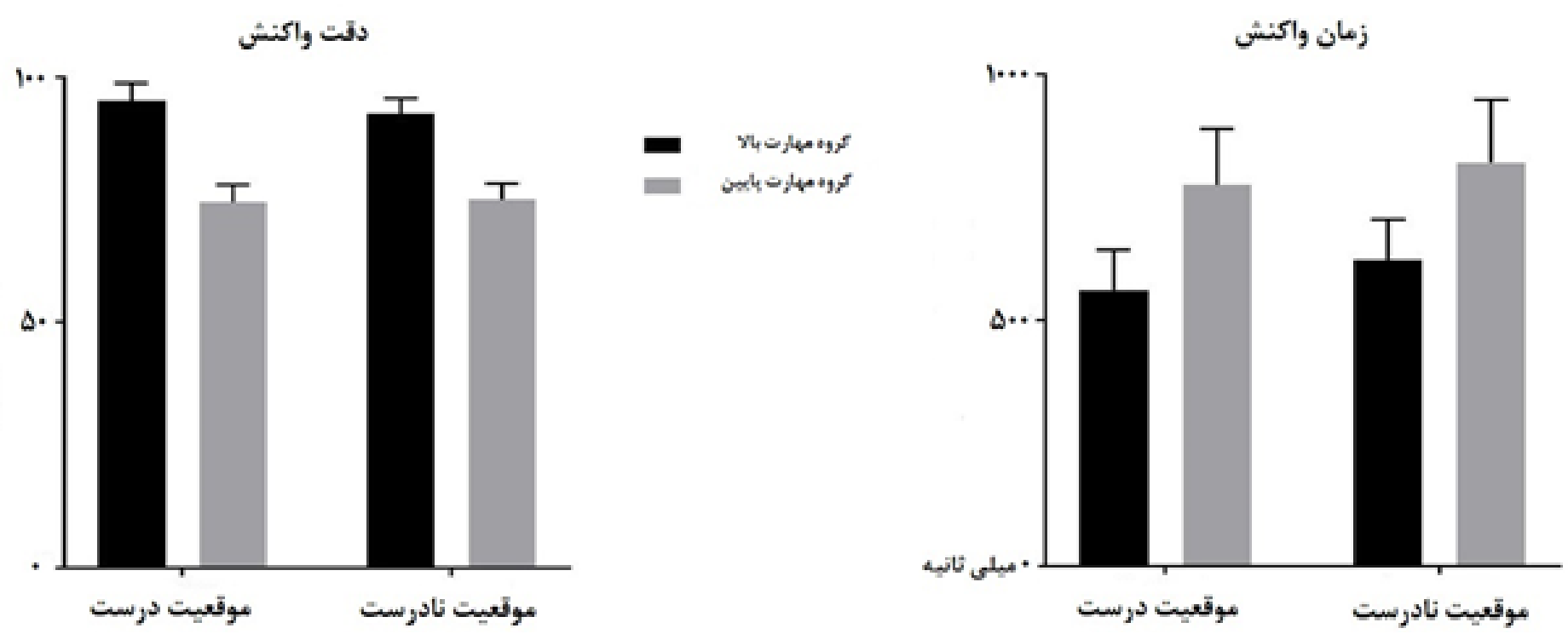

شكل r. دقت واكنش (درصد ياسخ هاى صحيح) و زمان واكنش (ميلى ثانيه) برحسب دو موقعيت آزمايشى به تفكيك دو كروه داراى مهارت بالا و پايين 

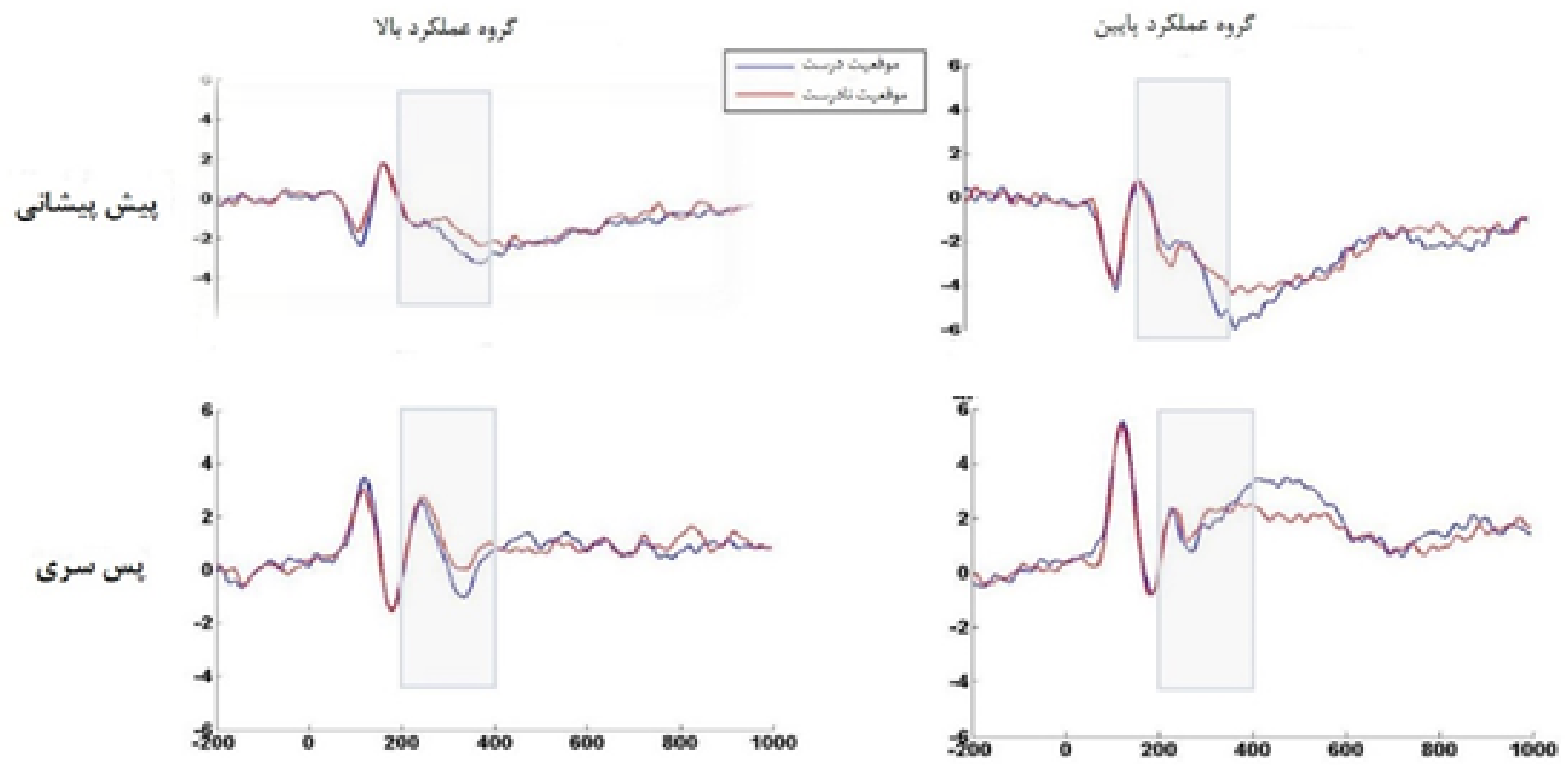

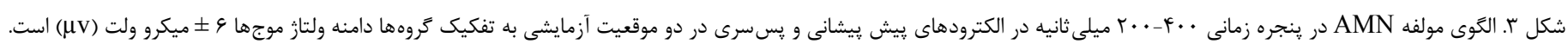
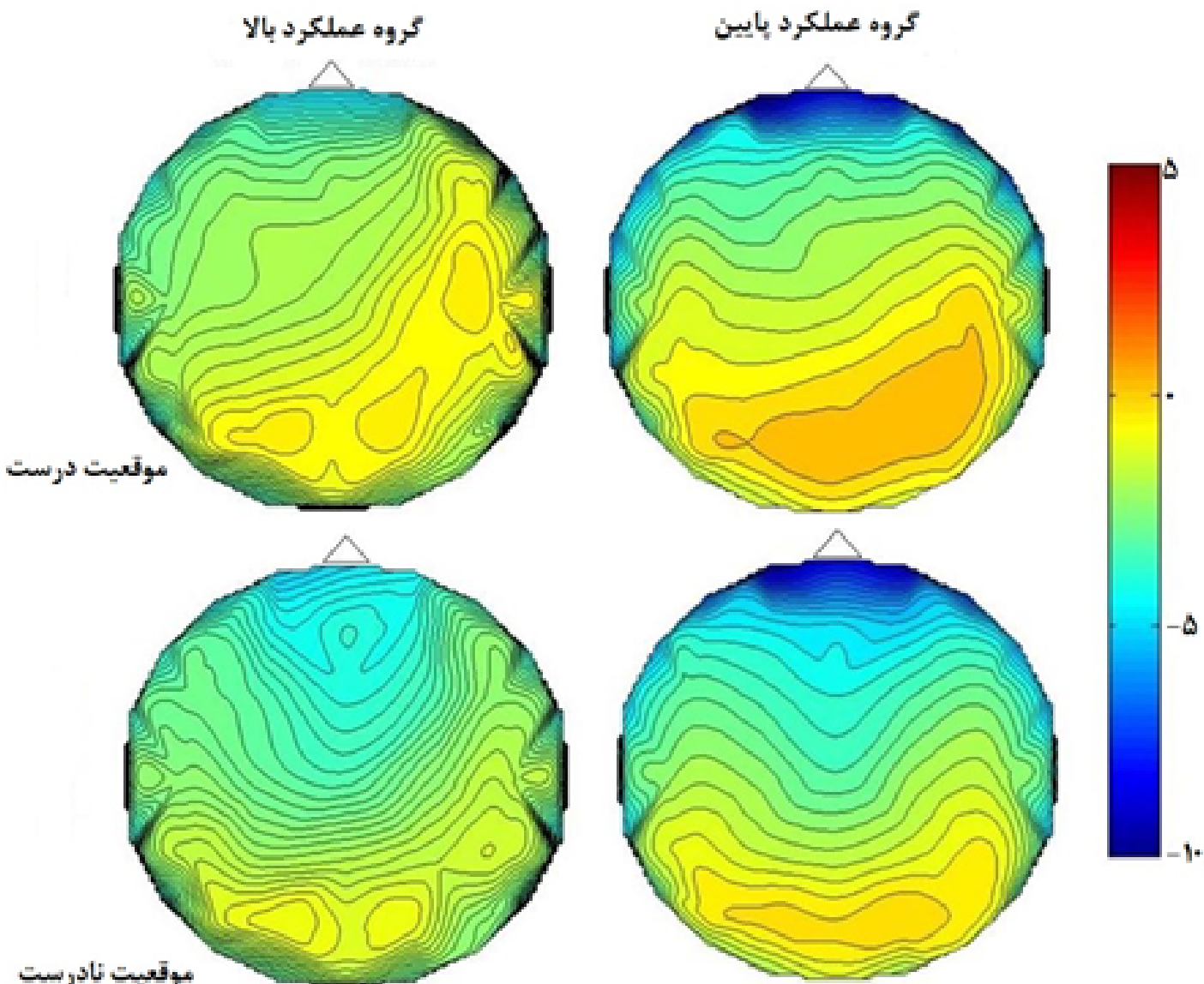

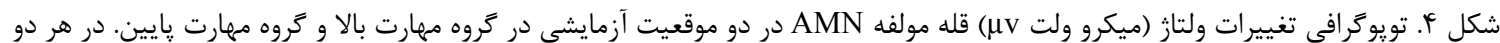

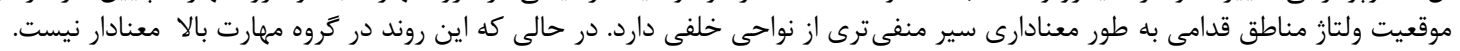


جدول r. نتايج آزمون تحليل واريانس مكرر

\begin{tabular}{|c|c|c|c|c|}
\hline$\eta_{p}^{2}$ & $\mathbf{P}$ & درجه آزادى & $\mathbf{F}$ & منبع تغييرات \\
\hline (TrT & $<\mid \cdot .1$ & 1 & IV/AqT & موقعيت \\
\hline . & .1 .14 & r & $r / 9 \cdot 1$ & نيمكره \\
\hline . IFTV & $<\mid \cdot \cdot 1$ & v & re/VVT & منطقه \\
\hline . /NAr & $<\mid \cdot \cdot 1$ & v & 11.91 & منطقه ×تروه \\
\hline$\cdot|T \Delta|$ & $<\mid \cdot \cdot 1$ & v & $\mid r / \cdot \Delta \Delta$ & موقعيت ×نيمكره \\
\hline$\cdot / \cdot \wedge \mathrm{V}$ &.$/ \cdot r$ & v & $r / 419$ & موقعيت ×منطقه \\
\hline
\end{tabular}

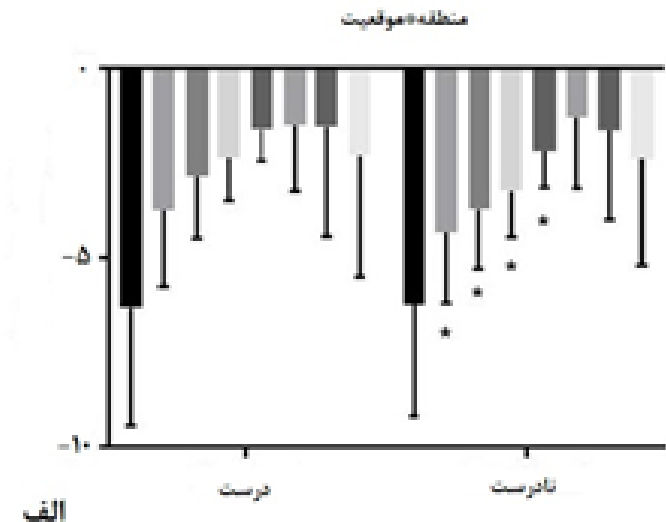

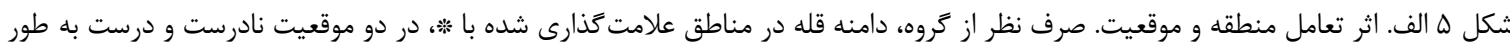

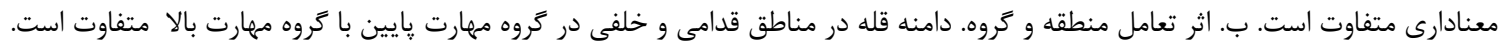

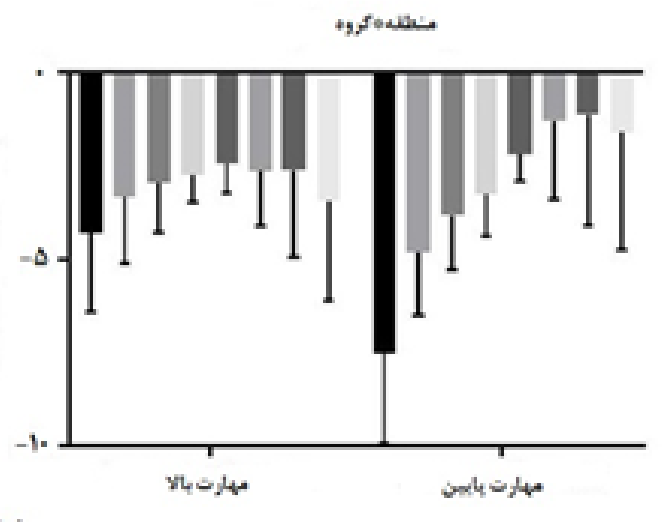

Dccipital
شناختى پايهاى براى حل مساله، مطالعات نشان دادند كه استراتزى

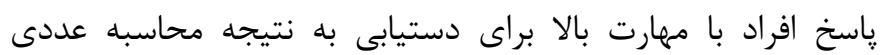

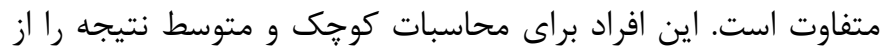
حافظه بازيابى مى كنند در حالى كه افراد كم مهارت فقط جواب هاى با اندازههاى كوجى را از حافظه بازيابى مى كنند و براى اندازههاى متوسط محاسبه مى كنند (1) (1).

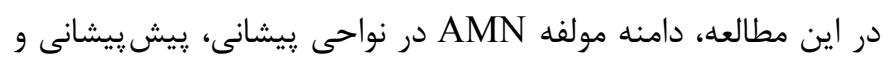

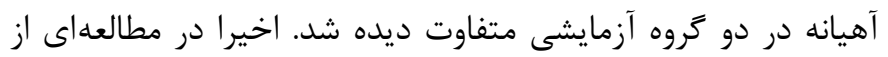

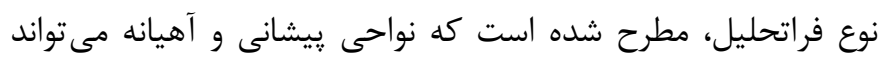

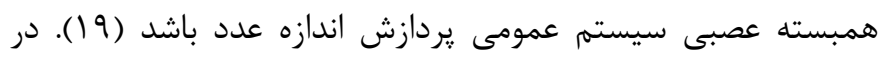

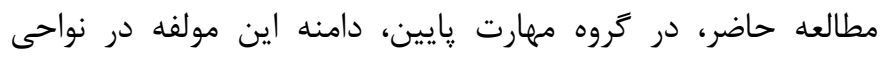
ييش ييشانى و يِشانى منفى تر مشاهده شد، اين يافته مى تواند مرتبط با يك سيستم يردازش عددى رشد نيافته (Underdeveloped) در

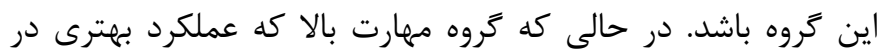
تكليف داشتند در منطقه آهيانه دامنه بزركترى نشان دادند. اين يافته 
ممكن است باز تاب تفاوت در نحوه فعال سازى در اين دو نوع ياسخ باشد.

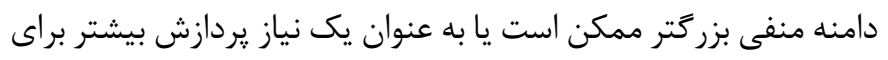

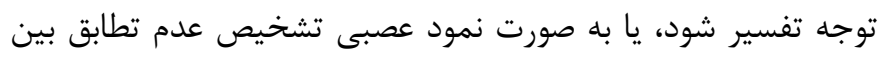

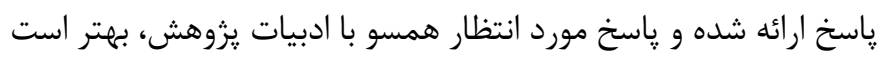

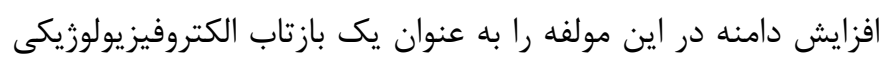
مرتبط با تشخيص عدم تطابق (Detecting stimulus mismatch)، و نه شاخص نياز به يردازش بيشتر، تفسير كنيم (YT). به طور خلاصه، دامنه متفاوت AMN كه در اين تحقيق در افراد مهارت

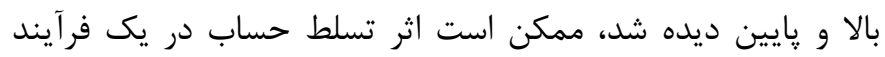

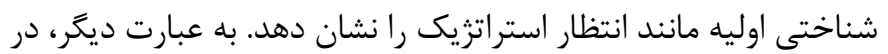

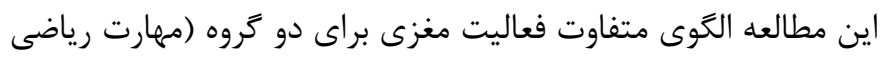

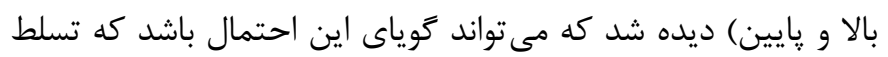

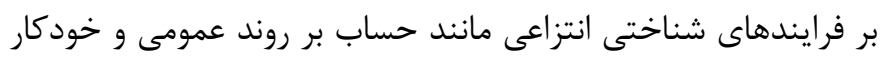

$$
\text { انتظار استراتزيك تأثير مى كذارد. }
$$

به طور كلى مطالعات رفتارى و شناختى كافى در مورد تفاوتهاى فردئ فردى در يردازش عدد و مقايسه عددى وجود دارد كه نشان مى دهند عملكرد افراد در اين فرايندهاى عددى مى تواند به عنوان يك پِيشبينى كننده

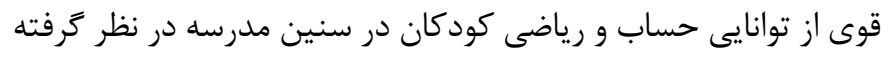

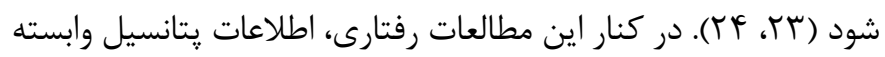

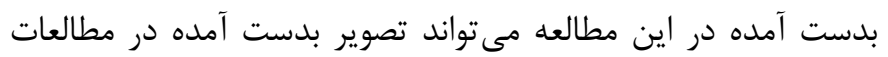
رفتارىشناختى را در اين حوزه كامل كند.

\section{نتيجه كيرى}

عوامل شناختى و يردازش اطلاعات نقش مهمى در مراحل يادَيرى به ويزه مراحل اوليه آن دارند. كاربرد علوم اعصاب براى مطالعه يردازش رياضى موجب درك فراترى از نظريههاى شناختى اوليه شده است. تفاوتهاى فردى در عملكرد رياضى توسط يك يتانسيل منفى به عنوان يك همبسته

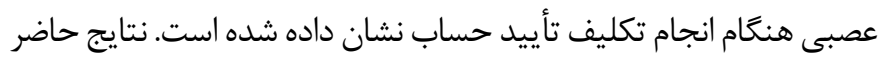

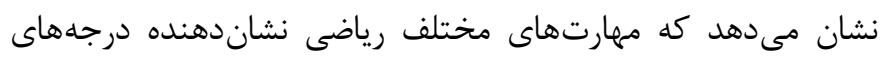

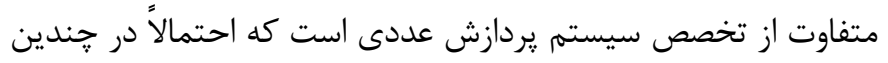

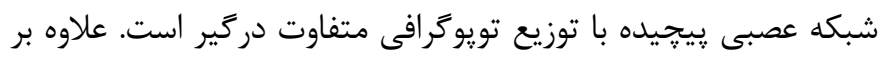

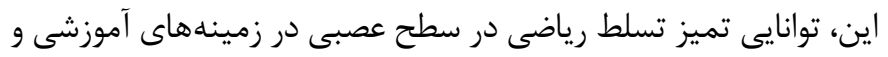

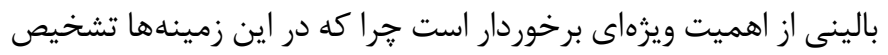
فرآيند عصبىشناختى مسئول در بروز اختلال مهم است.

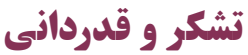
اين مقاله حاصل از رساله دكترى علوم اعصاب شناختى در دانشعاه تبريز
همسو با مطالعات قبلى كه نشان دادهاند كودكان با ناتوانى يادگيرى و

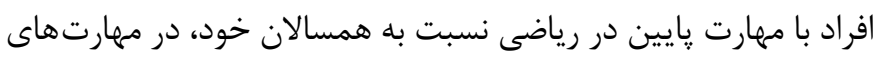

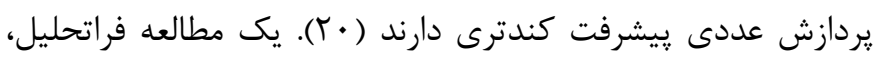

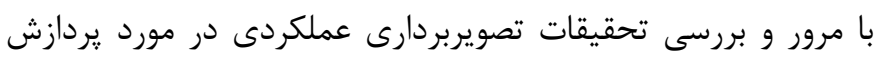

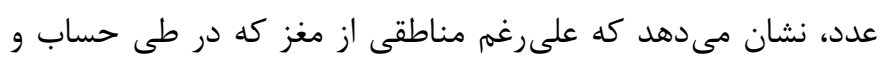

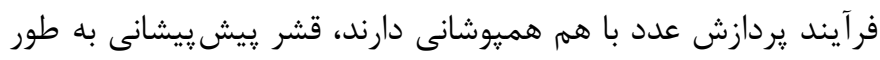

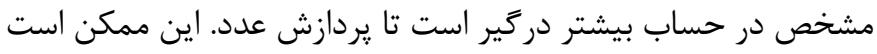
نشاندهنده مشاركت بيشتر منابع شناختى، مانند حافظه كارى، در حين انجام محاسبات باشد (· (Y).

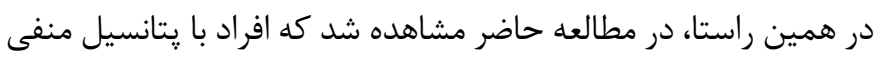

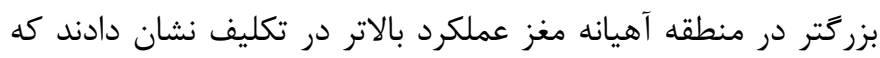

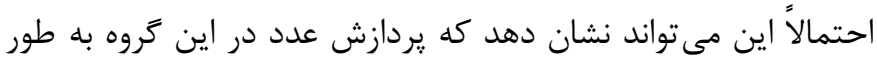

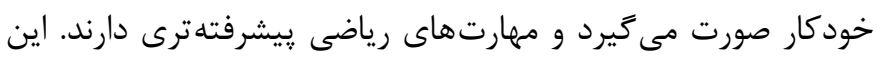

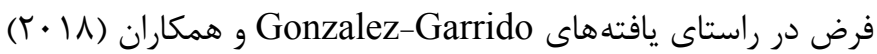
در تجزيه و تحليل همنوسانى الكتروانسفالوكرام كودكان با مهارتهاى دهاى دهاري مختلف رياضى مى باشد. آنان نشان دادند كه در كودكان با مهارت رياضى بالاتر، همنوسانى باند فركانسى بتا در نواحى آهيانه متمركز است و اين موضوع مىتواند بازتاب يردازش عددى در درجات بالاتر خودكار شده باديا و تخصصى تر شدن سيستم يردازش عددى در اين كودكان باشد (IV).

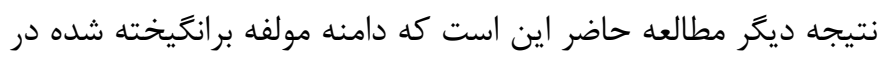

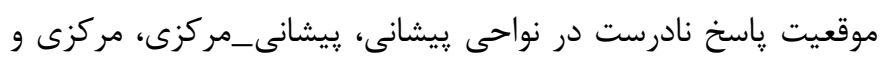

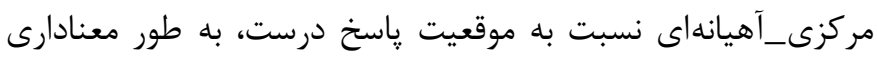
بزرَتر بود. اين نتيجه همسو با يافته هاى قبلى در مطالعات يتانسيل وابسته به رويداد در مورد يردازش عدد است. مطالعهاى مؤلفه منفى را فران در · rV ميلى ثانيه پٍ از محرك دوم (در تكليف تميز عددى موقعيت

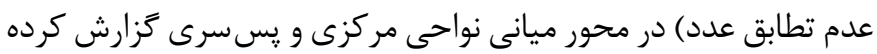
است (1). همجنين در مطالعهاى مشابه، يك مؤلفه منفى در موقعيت

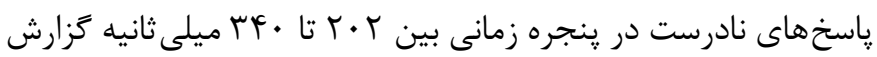

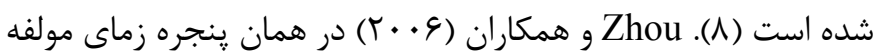
منفى N240, را گزارش كردند كه در موقعيت عدم تطابق عددى آشكار

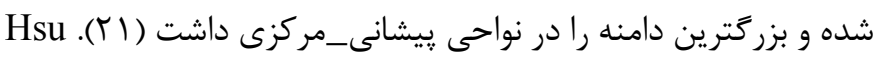

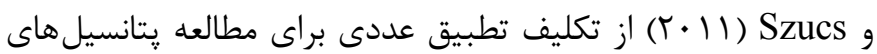
وابسته در فرايند يردازش عددى استفاده كردند و مولفه AMN را در الكترودهاى آهيانهاى مشاهده كردند. دامنه اين مولفه در موقعيت عدم تطابق بزر گتر بود. اين محقيق اين مؤلفه را يتانسيل وابسته به تشخيص

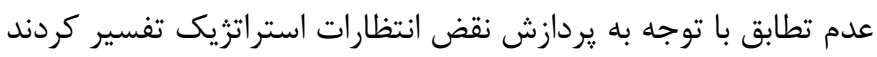

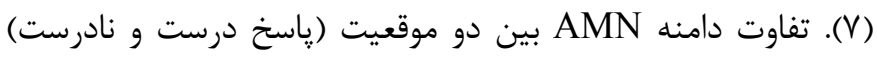




$$
\text { كه در انجام مطالعته است. از مديريت آزمايشگاه و تمام دانشجويان شركت كننده }
$$

\section{References}

1. Dehaene S, Piazza M, Pinel P, Cohen L. Three parietal circuits for number processing. Cognitive Neuropsychology. 2003;20(36):487-506.

2. Temple E, Posner MI. Brain mechanisms of quantity are similar in 5-year-old children and adults. Proceedings of the National Academy of Sciences. 1998;95(13):7836-7841.

3. Durand M, Hulme C, Larkin R, Snowling M. The cognitive foundations of reading and arithmetic skills in 7-to 10-year-olds. Journal of Experimental Child Psychology. 2005;91(2):113-136.

4. Holloway ID, Ansari D. Mapping numerical magnitudes onto symbols: The numerical distance effect and individual differences in children's mathematics achievement. Journal of Experimental Child Psychology. 2009;103(1):17-29.

5. Mundy E, Gilmore CK. Children's mapping between symbolic and nonsymbolic representations of number. Journal of Experimental Child Psychology. 2009;103(4):490-502.

6. Naatanen R, Paavilainen P, Rinne T, Alho K. The mismatch negativity (MMN) in basic research of central auditory processing: A review. Clinical Neurophysiology. 2007;118(12):25442590 .

7. Hsu YF, Szucs D. Arithmetic mismatch negativity and numerical magnitude processing in number matching. $\mathrm{BMC} \mathrm{Neu-}$ roscience. 2011;12(1):83.

8. Wang Y, Kong J, Tang X, Zhuang D, Li S. Event-related potential N270 is elicited by mental conflict processing in human brain. Neuroscience Letters. 2000;293(1):17-20.

9. Jost K, Hennighausen E, Rosler F. Comparing arithmetic and semantic fact retrieval: Effects of problem size and sentence constraint on event-related brain potentials. Psychophysiology. 2004;41(1):46-59.

10. Szucs D, Csepe V. The effect of numerical distance and stimulus probability on ERP components elicited by numerical
است و با حمايت مالى ستاد راهبرى توسعه علوم و فناورى هاى شناختى (كد

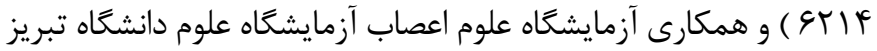

incongruencies in mental addition. Cognitive Brain Research. 2005;22(2):289-300.

11. Kong J, Wang Y, Zhang W, Wang H, Wei H, Shang H, et al. Event-related brain potentials elicited by a number discrimination task. Neuroreport. 2000;11(6):1195-1197.

12. Avancini C, Soltesz F, Szucs D. Separating stages of arithmetic verification: An ERP study with a novel paradigm. Neuropsychologia. 2015;75:322-329.

13. Nunez-Pena MI, Gracia-Bafalluy M, Tubau E. Individual differences in arithmetic skill reflected in event-related brain potentials. International Journal of Psychophysiology. 2011;80(2):143-149.

14. Farsad N, Alamolhodaei H, Moghimi A, Moghimi S, Jabbari Nooghabi M. A comparative study of cognitive processes in students with deep versus superficial knowledge on interpreting graphs of mathematical functions based on Event-Related Potential. Advances in Cognitive Sciences. 2020;21(4):46-57. 15. De Smedt B, Gilmore CK. Defective number module or impaired access? Numerical magnitude processing in first graders with mathematical difficulties. Journal of Experimental Child Psychology. 2011;108(2):278-292.

16. De Smedt B, Verschaffel L, Ghesquiere P. The predictive value of numerical magnitude comparison for individual differences in mathematics achievement. Journal of Experimental Child Psychology. 2009;103(4):469-479.

17. Gonzalez-Garrido AA, Gómez-Velazquez FR, Salido-Ruiz RA, Espinoza-Valdez A, Velez-Perez H, Romo-Vazquez R, et al. The analysis of EEG coherence reflects middle childhood differences in mathematical achievement. Brain and Cognition. 2018;124:57-63.

18. Mussolin C, Noel M-P. Automaticity for numerical magnitude of two-digit Arabic numbers in children. Acta Psycholog- 
ica. 2008;129(2):264-272.

19. Sokolowski HM, Fias W, Mousa A, Ansari D. Common and distinct brain regions in both parietal and frontal cortex support symbolic and nonsymbolic number processing in humans: A functional neuroimaging meta-analysis. Neuroimage. 2017; 146:376-394.

20. Geary DC, Hoard MK, Nugent L, Bailey DH. Adolescents' functional numeracy is predicted by their school entry number system knowledge. PloS One. 2013;8(1):e54651.

21. Zhou X, Chen C, Dong Q, Zhang H, Chen C, Qiao S, et al. Numerical distance effect in the N240 component in a number-matching task. Neuroreport. 2006;17(10):991-994.
22. Szucs D, Soltesz F, Czigler I, Csepe V. Electroencephalography effects to semantic and non-semantic mismatch in properties of visually presented single-characters: The N2b and the N400. Neuroscience Letters. 2007;412(1):18-23.

23. De Smedt B, Noel M-P, Gilmore C, Ansari D. How do symbolic and non-symbolic numerical magnitude processing skills relate to individual differences in children's mathematical skills? A review of evidence from brain and behavior. Trends in Neuroscience and Education. 2013;2(2):48-55.

24. Lyons IM, Price GR, Vaessen A, Blomert L, Ansari D. Numerical predictors of arithmetic success in grades 1-6. Developmental Science. 2014;17(5):714-726. 